\title{
"Antes de dançar o Coco era como estar no mundo, mas não existir": experiências dançantes de mulheres em contextos de políticas públicas culturais no Cariri Cearense ${ }^{1}$
}

\author{
"Antes de bailar el Coco era como estar en el mundo, pero no existir": \\ experiencias danzantes de mujeres en contextos de políticas públicas \\ culturales en el Cariri Cearense
}

\author{
"Before dancing the Coco was like being in the world, but not existing": \\ dancing experiences of women in contexts of cultural public policies in the \\ Cariri Cearense
}

Camila Mota Farias ${ }^{2}$

\begin{abstract}
Resumo
Objetivamos investigar a experiência dançante de mulheres brincantes de Coco no Cariri cearense, em um contexto marcado por políticas públicas culturais, compreendendo a relação existente entre o Estado, organizações não governamentais e os saberes/fazeres populares. A dança do Coco é uma prática de origem afroindígena encontrada no nordeste brasileiro, no Ceará destaca-se como dança de homens pescadores. Todavia, o espaço escolhido para estudo localiza-se no sertão, no qual esta dança é produzida, sobretudo, por mulheres agricultoras que assumem os papéis de dançadeiras e de mestras. Identificamos que estas mulheres se iniciaram na dança a partir de 1979, com o incentivo de políticas públicas culturais. Neste contexto foram formados grupos para dançar Coco, o que envolve uma espetacularização da dança, constituindo uma nova estética da brincadeira, marcada, por exemplo, pela inserção de um figurino próprio, fazendo-a migrar das comunidades rurais para os centros das cidades onde passaram a ser exibidas em palcos e praças. Apesar de este contexto deslocar territorialmente a dança e, também, promover novos significados e ritualizações em seu fazer, por meio de um jogo de poderes ocorre um processo de reinvenção dessas mulheres que passam a experimentar seus corpos e suas existências de uma outra forma, ressignificando o viver por intermédio do dançar. Assim, podemos produzir uma análise que compreenda as políticas culturais como mediadoras que, junto às experiências dos sujeitos, as suas subjetividades, promovem construções identitárias por meio de uma experimentação de fazeres poéticos.
\end{abstract}

Palavras-Chave: Dança do Coco; Experiências Dançantes; Políticas Públicas; Cariri.

\section{Resumen}

Objetivamos investigar la experiencia bailable de mujeres juguetones de Coco en el Cariri cearense, en un contexto marcado por políticas públicas culturales, comprendiendo la relación existente entre el Estado, las organizaciones no gubernamentales y los saberes/haceres populares. La danza del Coco es una práctica de origen afro-indígena encontrada en el nordeste brasileño, en Ceará se destaca como danza de hombres pescadores. Sin embargo, el espacio escogido para estudio se ubica en el sertão, en el cual esta danza es producida, sobre todo, por mujeres agricultoras que asumen los papeles de bailarinas y de maestras. Las mujeres empezaron a bailar partir de 1979, con el incentivo de políticas públicas culturales. En este contexto se formaron grupos para bailar a Coco, lo que implica una espectacularización de la danza, constituyendo una nueva estética de la broma, marcada, por ejemplo, por la inserción de un figurín propio, haciéndola migrar de las comunidades rurales a los

\footnotetext{
1 Artigo apresentado no Simpósio Temático Experiências estéticas com a arte enquanto cultura durante o II Seminário Latino-Americano de Estudos em Cultura - SEMLACult em Foz do Iguaçu/PR, Brasil, 2018.

${ }^{2}$ Mestra em História; Universidade Estadual do Ceará - Programa de Pós-graduação em Sociologia; Fortaleza, Ceará, Brasil; camilamotafarias@gmail.com.
} 
centros de las ciudades donde pasaron a ser exhibidas en escenarios y plazas. A pesar de que este contexto desplaza territorialmente la danza y, también, promover nuevos significados y ritualizaciones en su hacer, por medio de un juego de poderes ocurre un proceso de reinvención de esas mujeres que pasan a experimentar sus cuerpos y sus existencias de otra forma, resignificando el vivir a través del bailar. Así, podemos producir un análisis que comprenda las políticas culturales como mediadoras que pueden, junto a las experiencias de los sujetos, sus subjetividades, promover construcciones identitarias por medio de una experimentación de hacer poéticos.

Palabras claves: Danza del Coco; Experiencias Bailarinas; Políticas públicas; Cariri.

\begin{abstract}
We aim to investigate the dancing experience of Coco women in Cariri Ceará, in a context marked by public cultural policies, including the relationship between the State, non - governmental organizations and popular knowledge / practices. The Coco dance is a practice of Afro-indigenous origin found in the Brazilian northeast, Ceará stands out as a dance of men fishing. However, the space chosen for study is located in the hinterland, in which this dance is produced, above all, by women farmers who assume the roles of dancers and teachers. The women began to dance from 1979, with the encouragement of public cultural policies. In this context, groups were formed to dance to Coco, which involves a spectacularization of dance, constituting a new aesthetic of the game, marked, for example, by the insertion of an own costume, making it migrate from rural communities to the centers of the cities where they passed to be displayed on stages and squares. Although this context territorially displaces dance and also to promote new meanings and ritualizations in its doing, through a game of power occurs a process of reinvention of these women who begin to experience their bodies and their existence in another way, resignificando to live by means of dancing. Thus, we can produce an analysis that understands cultural policies as mediators that, together with the subjects' experiences, their subjectivities, promote identity constructions through an experimentation of poetic practices.
\end{abstract}

Keywords: Coconut Dance; Dancing Experiences; Public policy; Cariri.

\title{
1. A dança do Coco
}

A dança do Coco pode ser considerada como uma performance da cultura popular que remete às ancestralidades, sobretudo, africanas e indígenas. Esta dança traz o cantar-dançarbatucar como fundante da manifestação, que é marcada por uma alternância do ritual e do jogo, criando uma brincadeira que depende de uma figura-chave, o Mestre ou a Mestra, responsável pela transmissão dos saberes/fazeres e por conduzir a dança que é desenrolada a partir da estruturação de uma roda, na maioria dos casos. Segundo Zeca Ligiéiro (2011) estes elementos compõe características das performances culturais afro-brasileiras.

Todavia as ancestralidades da brincadeira estudada são reveladas, também, na historicidade da prática e através dos discursos dos brincantes. Estes remetem a uma "origem" africana e indígena, a estórias de índios e negros que cantavam e dançavam nas areias das praias nordestinas, ou ainda a vida dos escravos que nos engenhos junto ao trabalho forçado desenvolveram esta brincadeira, entre outras narrativas (ANDRADE, 2002).

O Coco se estrutura, principalmente, pelo uso de instrumentos de percussão, como o ganzá e o atabaque, possui uma estrutura poética-musical composta por solos e por refrão coral, respondido pelos dançadores. Esta prática pode ser encontrada, principalmente, no 
Nordeste Brasileiro. No Ceará, identificamos um maior destaque aos Cocos de Praia, estes estão constantemente participando de eventos culturais na capital cearense, eram grupos masculinos, atualmente vem ocorrendo uma modificação na estruturação destes grupos, que passaram a ser mistos e compostos por jovens. Assim, a dança no estado alencariano foi historicamente associada aos pescadores, sendo construída uma identidade da dança como brincadeira de pescadores, homens. Porém, no local escolhido para este estudo visualizamos uma diferente constituição do brincar.

\section{O Coco Caririense e as suas brincantes}

O Cariri é uma das quatorze regiões ${ }^{3}$ que compõe o Estado do Ceará. Possui uma área que corresponde a 16.350,40 $\mathrm{km}^{2}$ e agrega 28 municípios ${ }^{4}$. Seu nome deriva dos Kariris, grupo indígena que habitou o território antes de sua colonização. A região faz fronteira com outros Estados - ao sul com Pernambuco, ao oeste com Piauí e ao leste com a Paraíba -, inclusive: "Por ser território fronteiriço, sua formação política, econômica, histórica e cultural deve muito a fluxos migratórios que datam do século XVIII, quando se iniciou sua colonização" (SEMEÃO, 2014, p. 1).

Diferente do sertão nordestino, o Cariri não é caracterizado pela pobreza no solo, pelo clima semiárido ou pela vegetação da caatinga, em decorrência de se constituir como um vale em meio a Chapada do Araripe ${ }^{5}$, possui uma vegetação diversificada, solos férteis e clima mais ameno, o que gerou sua posição de destaque em razão do seu desenvolvimento econômico, ainda durante a Província, pelo cultivo de cana-de-açúcar e da pecuária. (PINHEIRO, 2010).

Segundo o historiador Carlos Rafael Dias (2014), durante o século XIX o Cariri destacou-se no plano estadual e nacional por sua participação em diversos eventos, como os movimentos emancipacionistas liberais e republicanos ocorridos em Pernambuco, a Revolução de 1817 e a Confederação do Equador, em 1824, destacando nomes como os de

\footnotetext{
${ }^{3}$ O Ceará é composto pelas regiões: Cariri, Centro Sul, Grande Fortaleza, Litoral Leste, Litoral Norte, Litoral Oeste/Vale do Curu, Maciço de Baturité, Serra da Ibiapaba, Sertão Central, Sertão de Canidé, Sertão de Crateús, Sertão dos Inhamuns, Sertão de Sobral e Vale do Jaguaribe. (O Povo, Fortaleza, 3 out. 2015, s/p).

${ }^{4}$ Abaiara, Barbalha, Caririaçu, Crato, Farias Brito, Grangeiro, Jardim, Juazeiro do Norte, Missão Velha, Várzea Alegre, Aurora, Barro, Brejo Santo, Jati, Mauriti, Milagres, Penaforte, Porteiras, Altaneira, Antonina do Norte, Araripe, Assaré, Campos Sales, Nova Olinda, Potengi, Salitre, Santana do Cariri e Tarrafas.

${ }^{5}$ De acordo com o geógrafo Basilio Silva Neto (2013, p. 52): “A Chapada do Araripe está localizada na porção central do Nordeste brasileiro, aproximadamente entre $7^{\circ}$ e $8^{\circ}$ de latitude sul e $38^{\circ} 30^{\prime}$ e $41^{\circ}$ de longitude oeste. Com aproximadamente 603.996,9ha, ela serve de limite aos estados do Ceará, ao norte, do Pernambuco, ao sul, e do Piauí a oeste. Da sua área total, 313.908,8039ha pertencem ao estado do Pernambuco, 261.204.6901ha ao Ceará e 28.883,43ha ao Piaúi".
} 
Bárbara de Alencar e de Tristão Gonçalves. Além do movimento liderado pelo político militar Joaquim Pinto Madeira, em 1831, que se desenvolveu como uma insurreição absolutista em decorrência da abdicação do Imperador Dom Pedro I ao trono brasileiro. A região, também, tornou-se conhecida pelos acontecimentos de cunho religiosos, como o milagre de Juazeiro do Norte, ocorrido em 1889, protagonizado por Padre Cícero Romão Batista e pela Beata Maria de Araújo, e como o Caldeirão de Santa Cruz do Deserto, ocorrido no século XX, liderado pelo Beato José Lourenço.

O Cariri é considerado o "celeiro cultural" do Estado do Ceará devido a sua significativa dinâmica cultural, é palco de diversos grupos de cultura popular, como bandas Cabaçais, grupos de Reisado, Maneiro Pau, Coco, entre outros. A pesquisa centra-se nos municípios de Juazeiro do Norte e do Crato, tendo em vista que foram neles que identificamos os sujeitos produtores da dança do Coco. As cidades estão localizadas, respectivamente, a 540 e a 529 quilômetros da capital cearenses e correspondem à Região Metropolitana do Carirí ${ }^{6}$, criada pela Lei Complementar Estadual n. 78, sancionada em 29 de junho de $2009 .{ }^{7}$

O Crato situa-se no sopé da Chapada do Araripe e faz divisa com o Estado de Pernambuco. Possui uma população estimada de 128.680 habitantes e uma área territorial de $1.176,467 \mathrm{~km}^{2}$. Juazeiro do Norte, que até 1911 era uma vila pertencente ao Crato, possui uma população aproximadamente de 266.022 habitantes e seu território corresponde a 248,832 $\mathrm{km}^{2}$, sendo o terceiro município mais populoso do Ceará. (IBGE, 2015).

Nestas duas cidades identificamos quatro grupos de Coco compostos só por mulheres, agricultoras, entre 50-80 anos, raras exceções. Estas mulheres narraram uma experiência com o dançar ocorrida em um outro tempo, sem datação definida, que remete a vivencia do Coco para pisar o chão das casas de taipa ou no como canto de trabalho na roça, esta experiência foi interrompida, porém ficou na memória destas mulheres, sendo acionada em momentos específicos o que culminou na formação dos quatro grupos estudados.

O primeiro grupo foi fundado em 1979, chama-se A gente do Coco da Batateira, foi organizado pela iniciativa de Mestra Edite Dias de Oliveira Silva, Dona Edite iniciou a brincadeira como atividade do $\mathrm{Mobral}^{8}$, levando adiante com as mulheres do bairro Batateira, na cidade do Crato, outro grupo que surgiu por interferência das políticas de educação foi o grupo Amigas do Saber, coordenado por Mestra Maria da Santa, que no sítio Quebra, no

\footnotetext{
${ }^{6}$ A Região Metropolitana do Cariri é composta por Juazeiro do Norte, Crato, Barbalha, chamado de triângulo caririense, e mais seis cidades: Caririaçu, Farias Brito, Jardim, Missão Velha, Nova Olinda e Santana do Cariri.

${ }^{7}$ Informações disponíveis no Plano Territorial de Desenvolvimento Rural Sustentável: Território Cidadania do Cariri, realizado pelo Instituto Agropolos do Ceará em 2010.

${ }^{8}$ Movimento Brasileiro de Alfabetização - MOBRAL foi fundado e desenvolvido durante a ditadura militar no Brasil pela Lei no 5.379 de dezembro de 1967, o movimento destinava-se à alfabetização de adultos.
} 
Crato, deu inicio ao dançar junto a uma turma do EJA ${ }^{9}$. Todos os outros grupos foram fundados nos anos 2000 e por interferência das políticas públicas culturais, são eles: Coco Frei Damião, criado por Marinêz Pereira do Nascimento, em Juazeiro do Norte, no ano de 2003; Coco da SCAN ${ }^{10}$, de Mestra Naninha, criado em 2011.

Todos estes grupos estão inseridos em um contexto intenso de diálogo com as políticas públicas culturais, concorrem a editais, constroem apresentações, possuem figurino, um tempo demarcado para execução da dança - cerca de trinta minutos, instrumentos, elementos cênicos, recebem cachês, entre outras coisas que poderíamos citar para caracterizar este contexto.

\section{Experiências Dançantes em contextos de políticas públicas culturais}

Com base nesta compreensão e em diálogo com o historiador da música, Francisco Damasceno (2008, p.12), que sugere a existência de uma experiência musical, que consiste na forma de produzir a música e no modo como esta produção cria éticas e estéticas de existência, ou seja, a música possui:

universos sensíveis e referenciados no universo do humano e do experiencial, que absorve dos campos humanos - sua textura e de dentro deles re-elabora a própria experiência humana $[\ldots]$ e assim, redimensiona a própria vida se constituindo ela própria em um vasto território de subjetividades e sentido.

Sugerimos, então, a existência de experiências dançantes, que se revelam na ultrapassagem dos códigos internos da dança - seja os passos, a dinâmica de organização, o figurino utilizado, as expressões e gestos, o canto, quando existe - se expandindo para a vida das pessoas, para as relações que estabelecem.

A partir deste entendimento, temos que as experiências dançantes das mulheres brincantes de Coco do Cariri cearense se dá em um contexto marcado por políticas públicas culturais, assim, aqui, vamos explanar rapidamente este contexto e como isso interfere no brincar, mas também como essas mulheres estão vivenciando essa manifestação cultural ao ponto de permitir uma outra experimentação de si.

Temos no Cariri que desde a década de 1960 essas manifestações populares passaram por transformações de deslocamento que visam um mostrar-se, apresentar-se, pois até então

\footnotetext{
${ }^{9}$ Escola destinada à Educação de Jovens e Adultos.

${ }^{10}$ SCAN é sigla que corresponde à Sociedade Cratense de Auxílio aos Necessitados, a mesma oferece atividades para idosas e idosos, localiza-se no Crato.
} 
elas estavam restritas aos espaços internos dos sítios, das roças, ou das casas de seus brincantes, sendo, inclusive proibidas no espaço públicos e taxadas de "bisonhas" e "primitivos". Esse deslocamento se intensificou a partir da década de 1960-70 com a atuação de Elói Teles, um radialista e folclorista local, que passou a divulgar nas rádios e também nas praças das cidades as brincadeiras populares, mas também com a criação sistemática e regular de eventos voltados a elas e com a influência do cenário nacional e estatual que corroboraram para maiores investimentos das politicas públicas nas culturas, já que desde a década de 1970 a cultura passa a ser discutida fortemente pela UNESCO e, no Ceará, começam a surgir atuações por parte dos governadores de investimento nas práticas culturais populares.

O que fez aparecer, por exemplo, as bandas cabaçais em publicação do Anuário do Ceará de 1973 como produtoras das "manifestações folclóricas cearenses mais autênticas e nativas, sobrevivendo, praticamente imune, às influências exteriores" (SAMPAIO, COSTA, 1973, p. 67). O discurso é elaborado com ideais de pureza, todavia estas permeavam a compreensão das culturas populares na época, além de associar a manifestação à "identidade cearense".

Sobre essa relação entre as políticas públicas culturais, a atuação de sujeitos locais e a dinâmica dos grupos culturais no Cariri, Mestra Edite ${ }^{11}$, produz uma síntese, compreendendo que:

\begin{abstract}
A cultura cresceu, em 70 existia os Aniceto, aí apareceu nós, o grupo Zé Cirilo, o grupo do Mestre Dedé de Luna e o grupo de seu Aldemir, pronto, era só esses grupos que tinha aqui no Crato, aí depois seu Dedé de Luna tem três grupos de dança, repare quanto a cultura cresceu, um só tem três grupos [...] aí o povo foi criando, apareceu Maria da Santa, criou um grupo de Coco na escola. Mulher, eu acho que a política pública e aquele governador que se chamava Lúcio Alcântara, ele foi quem cresceu essa cultura em Fortaleza, através dele foi passando um cachê que ele dá para os Mestres, uma complementação. Ele tava levando os grupos do Nordeste pra Fortaleza, fomos 4 vezes no Dragão do Mar. Logo no primeiro ano nós já foi com seu Elói, seu Elói era o Mestre de todos os grupos aqui do Crato, ele inventava tudo pra levar a gente pra fora. Aí o Mestre Elói foi incentivando a gente a fazer mais grupo [...] ele mandava fazer e o pessoal que sabia fazer ia fazendo e ia levando pra praça, pro museu, aquela turma de grupo, duas vezes no ano ele levava a gente pra dançar uma noite no Crato, depois levava pra outra cidade. (Crato - CE, 07 abr. 2014, grifos nossos).
\end{abstract}

A fala de "Dona" Edite é interessante, pois a Mestra interpreta o surgimento dos grupos culturais na região do Cariri como o "crescimento da cultura" por meio de incentivos

\footnotetext{
11 "Dona" Edite, que atualmente possui 74 anos, teve o primeiro contato com a dança ainda menina em Pernambuco, é Mestra do grupo de Coco A gente do Coco da Batateira.
} 
de políticas públicas no setor cultural e de agentes internos, como o Mestre Elói, proporcionando a saída de grupos para a realização de apresentações e recebimento de cachês.

Ainda na fala de Mestra Edite, para além das apresentações em praças e em museus, há o destaque dado ao Centro Dragão do Mar de Arte e Cultura como polo catalizador desses eventos culturais na década de 1990 e do projeto político estadual. Reafirmamos que este processo de deslocamento da prática cultural possui relação maior com os cenários nacional e estadual apresentados, com os movimentos de busca pela preservação do folclore, com a ampliação e legitimação da noção de patrimônio cultural, com o projeto de desenvolvimento regional a partir de investimentos no setor cultural.

Esse cenário faz com que a dança seja experimentada em uma outra lógica que se assemelha a da espetacularização. Segundo José Jorge de Carvalho (2010) a espetacularização consiste em uma "operação" que gera um movimento de captura, apreensão ou até confinamento, cria uma forma para um processo cultural que possui outra lógica. Temos de fato que este cenário provoca modificações na forma de se dançar, cantar e tocar Coco, provoca deslocamentos da manifestação.

Uma das alterações ocorridas neste processo de institucionalização está na estética por meio da incorporação de figurinos, ou de fardas, nas palavras de Mestra Edite:

Hoje existem vários grupos. Cada grupo é diferente do da antiguidade. Por exemplo, hoje a gente tem um calçado adequado, uma roupa adequada, um figurino. Cada qual quer tá mais bonito. E naquela época não era assim, era tudo pessoas simples, eles usavam tamanco de madeira para pisar o chão, hoje não, é alpercata artesanal de couro, é essas moleca, é umas farda diferente, é de chapéu. Hoje tem que ser tudo igual, se é de homem, as blusas e calças iguais, e se é de mulher, saia e blusa igual. (Crato - CE, 07 abr. 2014, grifos nossos).

A diferença apontada com relação à antiguidade está na utilização de uma "roupa adequada" que produz uma imagem de beleza e uma disputa desta entre os grupos, o que difere de antigamente, pois que a prática ocorria com seus integrantes utilizando roupas diversas, roupas de "passeio", não havia essa padronização e homogeneização, característica do espetáculo, como assinalou Carvalho (op. cit.). A utilização de figurino, ou farda, contribui para uma ideia de organização e de identificação do grupo e das mulheres como dançadeiras de Coco, diferente da plateia que está assistindo.

Porém, não podemos ter uma visão "canibalesca" e pensar que dentro desse contexto os sujeitos não são ativos e não produzem ressignificações que lhes afetam. Há um deslocamento da prática que sai de dentro das casas, como dança que se pisava o chão das casas de taipa, ou como brincadeira que acompanhava o roçado e a farinhada, para uma 
produção que se dá nas praças, em palcos, nas cidades. Cria-se um tempo determinado para uma brincadeira que acontecia sem demarcação de tempo, ou ainda um figurino que padroniza os brincantes. Porém, isso não quer dizer que houve uma desritualização do brincar, os rituais passam a ser outros, cria-se o ritual do ensaio, das reuniões, do lanchar junto antes e após a apresentação, da preparação, do vestir-se e do criar o figurino, entre outros.

Desta forma, o processo de espetacularização promoveu uma institucionalização das práticas em grupos que realizam produções culturais marcadas por transições e transformações. Segundo Carvalho (op. cit.), a espetacularização gera: a descontextualização das práticas culturais; suas transformações em objetos de consumo; a ressignificação de fora para dentro. As produções das mulheres coquistas são marcadas e influenciadas por este processo mais geral que envolve as práticas populares na contemporaneidade, porém essas consequências devem ser relativizadas ao pensarmos a realidade estudada.

Neste sentido, a primeira relativização relaciona-se a possibilidade de neste contexto atual essas mulheres conseguirem manter vivos os seus saberes/fazeres. A segunda relativização está no fato de que, mesmo ocorrendo uma descontextualização, ou desterritorialização da prática, novas contextualizações e territorializações são feitas a partir da transição do rural ao urbano, o que possibilita a criação de relações sociais e de outras formas de fazer os Cocos. A terceira relativização se expressa em que a produção dessas mulheres não adentra e é apropriada pela indústria cultural como um produto a ser consumido por uma massa, ela torna-se, de certo modo, objeto que é apropriado pela lógica produzida, principalmente, pelas políticas públicas, como representativa de uma identidade regional e por isso é transformada em um objeto a ser apresentado. Por fim, a quarta flexibilização dá-se por conta da ressignificação que passa a dança, esta não ocorre apenas como uma imposição de fora para dentro, mas tal ressignificação se dá em um processo dialético, permitindo que as mulheres ressignifiquem as suas existências através da experiência dançante que criam.

Em entrevista, a dançadeira Maria Neide, 67 anos, relembra como era a sua vida antes de dançar Coco:

\footnotetext{
Eu vivia era prisioneira, só da roça pro trabalho em casa, e sem sair pra nenhum canto, sem conhecer ninguém, sem conhecimento de ninguém, aí depois que eu entrei nesse Coco abençoado, aí comecei a andar mais ela aí [aponta para Mestra Edite], graças a Deus, tenho grande conhecimento de todo canto. Acho muito bom, de que eu tá em casa só pensando em coisa que não adianta, né? (Crato - CE, 7 abr. 2014, grifos nossos).
}

É como se na vida dessas mulheres a experimentação da dança demarcasse um antes e um depois, o antes é sempre reafirmado como o tempo do trabalho, o tempo do estar apenas 
em casa - na maioria das vezes trabalhando, de ser "prisioneira", como sugere a depoente, esse entendimento da vida, do corpo, de si, parece ser compartilhado pelas dançantes. Indicando que a experiência dançante dessas mulheres permite uma outra forma de significar a si, através de três elementos que mapeamos: o conhecimento, a descoberta da fala e a cidadania. Todos eles permitidos e adquiridos pela possibilidade do dançar leva-las a outros lugares diferentes dos lugares comuns destinados às mulheres, ou seja, por permitirem estar em lugares públicos, produzindo poéticas, sendo escutadas e reconhecidas por suas artes.

Logo, pensemos que a prática dessas mulheres ocorre dentro deste cenário de espetacularização das culturas populares, sendo influenciada por ele, mas não estando totalmente condicionada a sua lógica, em parte por não ser vendável o suficiente para interessar à indústria cultural e em parte pelas subjetividades e (atu)ações de suas produtoras que possibilitam ações criativas e inventivas, afetando as suas identidades.

\section{Referências}

ANDRADE, Mário de. Os Cocos. Belo Horizonte: Itatiaia, 2002.

CARVALHO, José Jorge de. 'Espetacularização' e ‘canibalização' das culturas populares na América Latina. Revista ANTHROPOLÓGICAS, Recife, v.21, p.39-76, 2010.

DAMASCENO, Francisco José Gomes. Experiências Musicais: em busca de uma aproximação conceitual. In: DAMASCENO, F.; MENDONÇA, A. (Org.). Experiências Musicais. Fortaleza: Prefeitura Municipal de Fortaleza - PMF / EDUECE, 2008.

DIAS, Carlos Rafael. Da flor da terra aos guerreiros cariris: representações e identidades do Cariri cearense (1855-1980). 2014. 169 f. Dissertação (Mestrado) - Programa de PósGraduação em História, Universidade Federal de Campina Grande, Campina Grande, 2014.

LIGIÉRO, Zeca. O Conceito de "motrizes culturais" aplicados às práticas perfomativas afrobrasileiras. Revista PÓS ciências sociais, v.8, n.16, p.129-144, jul/dez. 2011. ISSN 22369473. Disponível em: http://www.periodicoseletronicos.ufma.br/ Acesso em 11 jul. 2018.

PINHEIRO, Irineu. Efemérides do Cariri. Fortaleza: Edições UFC, 2010.

SAMPAIO, Dorian; COSTA, Lustosa da. Anuário do Ceará. Fortaleza: Stylus, 1973.

SEMEÃO, Jane. Os intelectuais do Instituto Cultural do Cariri e sua atuação na (re)invenção do Cariri Cearense (1953-1970). In: Encontro Estatual de História, 12., 2014, São Leopoldo. Anais do XII Encontro Estadual de História ANPUH/RS, São Leopoldo, 2014.

SILVA NETO, Basilio. Perda da vegetação natural na Chapada do Araripe (1975/2007) no estado do Ceará. 2013. 185 f. Tese (Doutorado) - Instituto de Geociências e Ciências Exatas, Universidade Estadual Paulista, Rio Claro, 2013. 